JURNAL ILMIAH MUOODDIMAH:

Jurnal IImu Sosial, Politikk Dan Humaniora

\title{
IMPLEMENTASI PROGRAM KELUARGA HARAPAN (PKH) TERHADAP KELUARGA PENERIMA MANFAAT (KPM) DI KOTA PEKANBARU
}

\author{
Saipul Al Sukri \\ Universitas Islam Negeri Sultan Syarif Kasim Riau \\ saipul.alsukri@gmail.com
}

\begin{abstract}
Abstrak
Persoalan kemiskinan dialami hampir seluruh negara di dunia, tak terkecuali di Indonesia. Program Keluarga Harapan (PKH) adalah salah satu upaya mengurangi angka kemiskinan di Indonesia. PKH merupakan program bantuan tunai bersyarat yang diadopsi dari program Conditional Cash Transfer (CCT). Sasaran dari program ini adalah peningkatan kualitas sumberdaya manusia yang berfokus pada kesehatan dan pendidikan. PKH di luncurkan pertama kali tahun 2007 dan baru di tahun 2013 diimplementasikan di Pekanbaru. Tujuan penelitian ini untuk menggambarkan bagaimana implementasi PKH di kota Pekanbaru. Implementasi ini terkait proses kegiatan yang secara bertahap dan konsisten dilakukan sesuai dengan mekanis medan prosedur yang telah diatur. Metode penelitian yang digunakan dalam penelitian ini adalah metode deskriptifkualitatif. Sumber data penelitian ini adalah primer dan sekunder. Teknik pengumpulan data dilakukan dengan observasi, wawancara, dan studi dokumen. Berdasarkan hasil penelitian, Implementasi PKH di Pekanbaru sudah cukup baik. Ini dapat dilihat dari setiap tahapan yang berjalan sesuai dengan alur kerja $\mathrm{PKH}$,namun dalam pelaksanaannya terdapat beberapa kendala dalam verifikasi komitmen dan pemutahiran di website E-PKH. Hal ini terjadi karena server tidak sanggup menampung lonjakan pengunjung yang serentak mengakses dalam waktu hampir bersamaan.
\end{abstract}

Kata Kunci:Implementasi, Program Keluarga Harapan, Kemiskinan.

\begin{abstract}
The problem of poverty is experienced by almost all countries in the world, including Indonesia. Program Keluarga Harapan (PKH) is one of the efforts to reduce poverty in Indonesia. PKH is a conditional cash transfer program adopted from the Conditional Cash Transfer (CCT) program. The aim of this program is to improve the quality of human resources that focus on health and education. PKH was first launched in 2007 and implemented in Pekanbaru at 2013. The purpose of this study is to illustrate how the implementation Program Keluarga Harapan in Pekanbaru. This implementation is related to the process and consistently accordance with the mechanisms and procedures that have been set. The research method used descriptive qualitative method. The data sources are primary data and secondary data. Data collection techniques are done by observation, interviews, and document studies. Based on the results of thisstudy, the Implementation of Program Keluarga Harapan in Pekanbaru was quite good. This can be seen from every step that goes according to the PKH workflow, but in its implementation there are several obstacles in verifying commitments and updates the E-PKH website. This happens because the server is unable to accommodate the surge of visitors who simultaneously access in almost the same time.
\end{abstract}

Keywords:Implementation, Program Keluarga Harapan, Poverty.

\section{PENDAHULUAN}

Kemiskinan merupakan satu dari banyak masalah yang menjadi perhatian hampir disetiap negara, tak terkecuali di Indonesia. Kemiskinan juga merupakan masalah sosial yang senantiasa relevan untuk dikaji secara berkelanjutan. Hal ini karena gejala yang semakin meningkat dan terus sejalan dengan krisis multidimensional 
yang masih dihadapi oleh bangsa Indonesia (EdiSuharto, 2017).

Tingkat kemiskinan yang ada di rumah tangga atau keluarga umumnya berhubungan dengan pendidikan dan kesehatan. Rendahnya Penghasilan keluarga miskin berakibat pada ketidakmampuan mereka dalam memenuhi kebutuhan dalam bidang kesehatan. Perawatan kesehatan ibu hamil di keluarga sangat miskin seringkali tidak memadai, seringkali menyebabkan kesehatan yang buruk bagi bayi yang baru lahir. Bahkan tak jarang menyebabkan bayi meninggal. Angka kematian ibu hamil dapat disebabkan oleh tidak adanya tenaga medis saat lahir, kurangnya fasilitas kesehatan dan masih banyak rumah tangga miskin yang lebih memilih persalinan secara tradisional (dukun kampung) dari pada petugas medis.

Keluarga dengan daya beli rendah juga tidak dapat memberikan pendidikan yang layak bagi anak-anak mereka. Sebagian besar anak-anak meraka tidak bersekolah karena harus mencari nafkah (Konig, 2011). Ketidakmampuan ini menyebabkan generasi mendatang terjebak dalam lingkaran kemiskinan.

Masalah kemiskinan tidak dapat dipisahkan dari strategi negara dalam mewujudkan kesejahteraan sosial bagi masyarakat. Dalam alineake empat pembukaan Undang-Undang Dasar 1945 menyatakan bahwa pemerintah wajib melindungi segenap bangsa Indonesia, memajukan kesejahteraan umum, dan mencerdaskan kehidupan bangsa. Dalam upaya memajukan kesejahteraan umum, pemerintah bertanggung jawab memelihara fakir miskin, anak terlantar, mengembangkan sistem jaminan sosial, perlindungan sosial,dan pemberdayaan masyarakat,tidak mampu, kurang beruntung, rentan,dan hidup dalam keadaan miskin. Penjelmaan itu dijumpai pada pasal27, 33,dan pasal34 UUD1945. Sedangkan dalam pelaksanaan mencerdaskan kehidupan bangsa dapat kita jumpai pada Pasal 31 UUD 1945 yang berbunyi "Setiap warga negara berhak mendapat pendidikan".

Dalam perkembangannya, upaya penurunan angka kemiskinan sudah dilakukan dalam banyak program

Volume 4, Nomor 1, Pebruari 2020 pemerintah. Program ini dilaksanakan dalam rangka perlindungan sosial untuk melindungi masyarakat miskin dan rentan (Sagala et al, 2016). Program penanggulangan kemiskinan yang sudah diterapkan oleh pemerintah, seperti Program Pengembangan Kecamatan (PPK), PNPM Mandiri, Bantuan Langsung Tunai (BLT), Bantuan beras untuk Rakyat Miskin (RASKIN), Bantuan Pangan NonTunai (BPNT), Bantuan Operasional Sekolah (BOS), Jaminan kesehatan Daerah (Jamkesda), Kartu Indonesia Pintar(KIP), Kartu Indonesia Sehat (KIS), Program Keluarga Harapan (PKH), dan lainlain.

Dari sejumlah program yang telah dilaksanakan oleh pemerintah itu, penulis akan mengkaji tentang Program Keluarga Harapan (PKH). PKH adalah inisiatif pemerintah untuk mengembangkan sistem perlindungan sosial dan pengentasan kemiskinan dengan mengadopsi Conditional Cash Transfer (Irmayani, 2015) yaitu bantuan tunai bersyaratdan merupakan salah satu program bantuan sosial yang diadopsi dari program yang telah dilaksanakan beberapa negara berkembang dan berpenghasilan rendah.

Peraturan Menteri Sosial RI Nomor1 Tahun 2018 menyebutkan bahwa "PKH adalah program pemberian bantuan sosial bersyarat yang ditujukan kepada fakir miskin yang memiliki komponen kesehatan, pendidikan dan kesejahteraan sosial yang terdaftar dalam data terpadu program penanganan fakir miskin."

Berikut adalah tabel perkembangan jumlah Keluarga Penerima Manfaat (KPM) PKH di Indonesia sejak 2007 hingga 2018.

Tabel 1. Jumlah KPM PKH 2007-2018

\begin{tabular}{|l|c|c|c|c|c|}
\hline No & Th & Prov & Kab/Kota & Kec & Jlh KPM \\
\hline 1. & 2007 & 7 & 48 & 337 & 387.947 \\
\hline 2. & 2008 & 13 & 70 & 637 & 620.848 \\
\hline 3. & 2009 & 13 & 70 & 781 & 726.376 \\
\hline 4. & 2010 & 20 & 88 & 946 & 774.293 \\
\hline 5. & 2011 & 25 & 119 & 1.387 & 1.052 .201 \\
\hline 6. & 2012 & 33 & 169 & 2.001 & 1.454 .655 \\
\hline 7. & 2013 & 33 & 336 & 3.417 & 2.362 .533 \\
\hline 8. & 2014 & 34 & 418 & 4.870 & 2.871 .827 \\
\hline 9. & 2015 & 34 & 472 & 6.080 & 3.511 .088 \\
\hline 10. & 2016 & 34 & 504 & 6.402 & 5.981 .528 \\
\hline 11. & 2017 & 34 & 509 & 6.730 & 6.228 .810 \\
\hline 12. & 2018 & 34 & 512 & 7.214 & 10.000 .000 \\
\hline
\end{tabular}

Sumber: Pedoman Pelaksanaan PKH, 2019 
Pelaksanaan $\mathrm{PKH}$ yang sudah berjalan lebih dari 6 tahun di Pekanbaru menjadi alasan peneliti untuk mengetahui bagaimana implementasiprogram ini, adakah pengurangan angka kemiskinan atau apakah program ini sudah mampu meningkatkan taraf hidup peserta/ KPM PKH.Pembahasan akan difokuskan pada mekanisme pelaksanaan PKHdi kota Pekanbaru pada tahapan, sosialisasi, pendataan calon peserta, pertemuan awal dan validasi, penyaluran bantuan, Pendampingan, P2K2, verifikasi komitmen dan pemutakhiran data.

\section{METODE PENELITIAN}

Penelitian ini menggunakan metode deskriptif kualitatif. Moleong (2016) menjelaskan bahwa Penelitian deskriptif dilakukan untuk mendapatkan gambaran keadaan obyek penelitian pada saat sekarang sebagaimana adanya berdasarkan fakta-fakta. Dalam penelitian ini data diperoleh dari sumber primer dan sekunder dengan pendekatan purposive sampling.Sugiono (2007) menyatakan bahwa purposive sampling yaitu sebuah teknik penentuan informan berdasarkan pada pertimbangan tertentu. Data sekunder diperoleh dari dokumendokumendan informasi media sedangkan data primer diperoleh melalui observasi, dokumentasi dan wawancara mendalam. Informan dalam wawancara adalah PendampingPKH, Administrator Pangkalan Data (APD), Koordinator dan Supervisor PKH Kota Pekanbaru. Dalam penelitian ini, teknik analisis data yang digunakan adalah analisis data model Miles dan Huberman atau disebut model Interaktif. Komponen-komponen analisis data mencakup reduksi data, penyajian data, dan penarikan kesimpulan secara interaktif saling berhubungan sebelum dan sesudah pengumpulan data (Salim,2006:22-23).

\section{PEMBAHASAN}

Program

Keluarga Harapan

merupakan produk kebijakan untuk menanggulang permasalahan kemiskinan yang mulai diimplementasikan tahun 2007. Awalnya $\mathrm{PKH}$ hanya menjangkau di 7 Provinsi, 48 Kabupaten/Kota dan melayani 387.928 KPM. Selanjutnya PKH mulai dilaksanakan diseluruh wilayah Indonesia pada tahun 2014. Pekanbaru menjalankan $\mathrm{PKH}$ di tahun2013. Saat ini PKH hanya menjangkau 7 Kecamatan, namun sejak tahun 2017, PKH sudah ada di 12 kecamatan.

\section{Proses Implementasi PKH di Kota Pekanbaru \\ Program Keluarga Harapan (PKH)} bertujuan untuk memberikan bantuan kepada Kelompok Penerima Manfaat (KPM) untuk mengurangi beban mereka melalui Bantuan Langsung Tunai Bersyarat, dengan sasaran jangka pendek dan jangka panjang. Sasaran jangka pendek bertujuan untuk membantu pengeluran KPM dengan bantuan uang tunai, sedangkan sasaran jangka panjang bertujuan mempersiapkan generasi muda yang sehat dan cerdas. Dalam pelaksanaan $\mathrm{PKH}$ di Kota Pekanbaru, terdapat personel dari Unit Pelaksana Program Keluarga Harapan (UPPKH). Kehadiran pendamping dibutuhkan guna membantu peserta $\mathrm{PKH}$ dalam memperoleh hak yang selayaknya mereka terima dari Pemerintah. Pendamping PKH juga memiliki tugas pokok antar alain validasi, pertemuan bulanan dan verifikasi. Tugas pokok ini membantu dalam mendeteksi segala permasalahan dan melakukan tindak lanjut dalam kurun waktu cepat dan tepat.

Berdasarkan hasil wawancara dengan Pendamping $\mathrm{PKH}$, Koordinator Kota, penerima program dan pelaksana program diketahui bahwa mekanisme pelaksanaan Program Keluarga Harapan di Kota Pekanbaru berlangsung melalui tahapantahapan sebagaiberikut:

\section{Proses Sosialisasi dan Pendataan RTSM}

Dalam pelaksanaan $\mathrm{PKH}$ yang pertama-tama dilakukan oleh pemerintah adalah sosialisasi program. Proses sosialisasi program dilakukan secara terbuka mulai dari Pemerintah Pusat (Kementerian Sosial) sampai ke tingkat RT/RW. Setelah proses sosialisasi lalu proses pendataan Rumah Tangga Sangat Miskin (RTSM).

Sejak 2017, dalam upaya mengubah sasaran program, data penerima manfaat PKH diambil dari Basis Data Terpadu (BDT) hasil pendataan program perlindungan 
sosial (PPLS) tahun 2015, yang dikelola oleh tim nasional percepatan penanggulangan kemiskinan (TNP2K). Data tersebut kemudian disampaikan ke sekretariat UPPKH pusat yang didalamnya sudah berisi nama dan alamat calon peserta PKH per Provinsi dan Kabupaten/ Kota. Data ini kemudian menjadi bahan untuk penetapan calon peserta $\mathrm{PKH}$ yang selanjutnya disebut kelompok penerima manfaat (KPM).

Selanjutnya sasaran $\mathrm{PKH}$ yang berbasis Rumah Tangga, sejak 2017 ditujukan kepada keluarga.Perubahan ini dianggap relevan dengan peningkatan kualitas sumber daya manusia untuk memutus rantai kemiskinan antar generasi. Setiap keluarga berhak menerima bantuan tunai apabila memenuhi kriteria kepesertaan program. Bantuan dana tunai PKH diberikan kepada ibu atau perempuan dewasa selanjutnya disebut Pengurus Keluarga.

\section{Pertemuan Awal dan Validasi}

Agar calon KPM $\mathrm{PKH}$ memiliki pemahaman dan mengetahui syarat dan kewajiban peserta, maka selanjutnya pendamping $\mathrm{PKH}$ melakukan pertemuan awal berupa Sosialisasi Program. Sosialisasi Program mengundang seluruh calon peserta dan ditambah dengan unsur pejabat Desa/Lurah. Pada saat pertemuan, pendamping $\mathrm{PKH}$ menyampaikan hal-hal berikut: (a) Informasi tentang tujuan $\mathrm{PKH}$; (b) Menjelaskan syarat eligible menjadi peserta $\mathrm{PKH}$; (c) Menjelaskan hak dan kewajiban peserta yaitu komitmen pendidikan dan kesehatan; (d) Penjelasan tentang pelayanan kesejahteraan sosial; dan (e) Menjelaskan tentang penyaluran bantuan.

Sosialisasi program dalam pertemuan awal ini tidak hanya sebagai sarana informasi program tapi kegiatan ini juga digunakan sebagai validasi data. Menurut narasumber, hal-hal yang bisa digali dalam pertemuan ini adalah pencocokan data awal yang diperoleh dari pusat dengan data calon peserta. Salain itu fakta kondisi terkini KPM juga bisa diketahui, baik itu tingkat ekonomi maupun kriteria komponen. Calon peserta yang kondisi ekonominya sudah baik dan yang tidak memiliki kriteria kepesertaan (non-eligible) kemudian diberikan penjelasan bahwa mereka tidak dapat di teruskan menjadi peserta $\mathrm{PKH}$. Bagi calon KPM yang memiliki kriteria program (Eligible) selanjutnya menandatangani komitmen pada formulir validasi.

Sebelum ditetapkan menjadi peserta $\mathrm{PKH}$, calon KPM akan didata dan diverifikasisesuai kriteria keluarga yang memenuhi komponen. Ada tigakriteria komponenpenerimabantuan $\mathrm{PKH}$ yaitu:

a) Kriteria komponen kesehatan, meliputi: Ibu hamil/ menyusui dan anak berusia 0-6 tahun.

b) Kriteria komponen pendidikan, dapat meliputi: Anak yang bersekolah di SD/MI, Anak SMP/MTs, Anak SMA/MA atau sederajat dan Anak usia 6-21 tahun yang belum menyelesaikan wajib belajar 12 tahun.

c) Kriteria komponen kesejahteraan sosial, meliputi: Lanjut usia yang sudah berumur 70 tahun dan penyandang disabilitas berat.

Ketiga komponen penerima bantuan $\mathrm{PKH}$ tersebut harus terpenuhi minimal salah satu atau lebih.

\section{Penyaluran Bantuan}

Bantuan PKH diberikan dan di terima oleh ibu atau wanita dewasa dalam keluarga yang disebut sebagai pengurus keluarga. Sejak tahun 2017 (PP 63, 2017) pemerintah bekerjasama dengan pihak bank dalam mencairkan dana bantuan $\mathrm{PKH}$ dengan menunjuk bank pemerintah dalam penyalurannya. Bank penyalur tersebut terhimpun dalam Bank Himbara (Himpunan Bank Negara) yang terdiri dari Bank BNI, BRI, BTN dan Bank Mandiri. Setiap KPM mendapatkan bantuan berdasarkan jumlah komponen yang dihitung menurut ketentuan penerimaan bantuan $\mathrm{PKH}$, baik komponen pendidikan, kesehatan atau komponen kesejahteraan sosial. Hal ini dinilai lebih adil menurut sebagian KPM karena selama ini mereka yang mempunyai jumlah anak atau komponen yang labih dari keluarga lainnya memperoleh bantuan yang sama padahal pengeluaran rumah tangga mereka jauh berbeda. Bantuan diberikan maksimal untuk 4 jiwa dalam satu keluarga. Selain itu, juga diberikan bantuan tetap untuk setiap keluarga yang mereka terima sekali dalam satu tahun. Besaran bantuan yang diterima oleh KPM yaitu sebagai berikut: 

1) Bantuan Tetap untuk Setiap Keluarga Reguler
Rp. 550.000,- / keluarga/ tahun
PKH AKSES : Rp. 1.000.000,-/ keluarga / tahun
2) Bantuan berdasakan jumlah komponen

Tabel 2. IndeksBantuanPKH

\begin{tabular}{|l|l|}
\hline IndeksBantuan & $\begin{array}{c}\text { Bantuan/RTSM/ } \\
\text { Tahun }\end{array}$ \\
\hline Ibu hamil/ menyusui & Rp. 2.400.000,-- \\
\hline Anak usia dini & Rp. 2.400.000,-- \\
\hline Pendidikan setara SD/MI & Rp. $900.000,-$ \\
\hline Pendidikan setara SMP/MTs & Rp. 1.500.000,- \\
\hline Pendidikan setara SMA/MA & Rp. 2.000.000,-- \\
\hline $\begin{array}{l}\text { Lanjut Usia dan Disabilitas } \\
\text { Berat }\end{array}$ & Rp. 2.400.000,-- \\
\hline
\end{tabular}

\section{Pendampingan dan Pelaksanaan P2k2}

Sumber daya manusia $\mathrm{PKH}$ atau bisa disebut pendamping sosial sangat diperlukan untuk menunjang pelaksanaan $\mathrm{PKH}$ agar berjalan dengan lancar. Informasi yang diterima dari hasil wawancara dengan Bapak Feron sebagai APD PKH Kota Pekanbaru menyampaikan:

"Saat ini SDM PKH di Kota Pekanbaru berjumlah 70 orang, dengan rincian 1 orang Koordinator Kota, 1 orang Supervisor, 3 orang Admininstrator Pangkalan Data dan 65 orang Pendamping Sosial." (wawancara, 15 Desember 2019)

Data penerima PKH setiap kecamatan di Kota Pekanbaru selengkapnya dapat dilihat di tabel 3 berikut ini:

\begin{tabular}{|c|c|c|c|}
\hline No & $\begin{array}{c}\text { Nama } \\
\text { kecamatan }\end{array}$ & $\begin{array}{c}\text { Jumlah } \\
\text { Pendamping }\end{array}$ & $\begin{array}{c}\text { Jumlah } \\
\text { penerima } \\
\text { PKH }\end{array}$ \\
\hline 1 & Bukit Raya & 4 & 694 Orang \\
\hline 2 & Lima puluh & 2 & 525 Orang \\
\hline 3 & $\begin{array}{c}\text { Marpoyan } \\
\text { damai }\end{array}$ & 6 & 1.127 Orang \\
\hline 4 & $\begin{array}{c}\text { Payung } \\
\text { Sekaki }\end{array}$ & 5 & 976 Orang \\
\hline 5 & $\begin{array}{c}\text { Pekanbaru } \\
\text { Kota }\end{array}$ & 3 & 541 Orang \\
\hline 6 & Rumbai & 8 & 1.652 Orang \\
\hline 7 & $\begin{array}{c}\text { Rumbai } \\
\text { pesisir }\end{array}$ & 7 & 1.324 Orang \\
\hline 8 & Sail & 2 & 233 Orang \\
\hline 9 & Senapelan & 4 & 666 Orang \\
\hline
\end{tabular}

Volume 4, Nomor 1, Pebruari 2020

\begin{tabular}{|c|c|c|c|}
\hline 10 & Sukajadi & 4 & 624 Orang \\
\hline 11 & Tampan & 9 & 1.765 Orang \\
\hline 12 & $\begin{array}{c}\text { Tenayan } \\
\text { raya }\end{array}$ & 11 & 2.341 Orang \\
\hline & Jumlah & $\mathbf{6 5}$ & $\begin{array}{c}\mathbf{1 2 . 4 6 8} \\
\text { Orang }\end{array}$ \\
\hline
\end{tabular}

Sumber: APD Kota Pekanbaru, 2019.

Dari hasil pemaparan terkait jumlah SDM PKH jika di bandingkan dengan jumlah KPM maka rata-rata KPM yang didampingi oleh setiap pendamping lebih kurang 200 orang KPM PKH.

Selain pertemuan kelompok rutin pendamping juga melaksanakan Family Development Session (FDS) atau pertemuan peningkatan kemampuan keluarga (P2K2) sejak tahun 2015. Penyampaian P2K2 berupa film pendek dan modul dengan beragam tema. Melalui materi tersebut pendamping memberikan motivasi dan edukasi kepada KPM PKH. Beberapa modul utama yaitu Modul Kesehatan dan Gizi, Modul Pengelolan Keuangan Keluarga, Pendidikan dan Pengasuhan Anak, Modul Perlindungan Anak, dan Modul Kesejahteraan Sosial. Dari pemberian materi tersebut diharapkan ada perubahan pola pikir yang nantinya berwujud dalam perubahan perilaku KPM. Ibu Ainil, Supervisor PKH Kota Pekanbaru mengatakan;

"Dalam upaya upgrading kompetensi Pendamping PKH, pada tahun 2019 Balai Besar Diklat Pendidikan dan Pelatihan Kesejahteraan Sosial (BBDPPKS) Regional 1 Sumatera melaksanakan pendidikan dan pelatihan Pertemuan Peningkatan Kemampuan Keluarga (P2K2), ini digunakan sebagai upaya menambah wawasan pendamping dalam memberikan materi nantinya ke ibu-ibu KPM. "(wawancara, 27 Desember 2019)

\section{Verifikasi Komitmen dan \\ Pemutakhiran Data}

Verifikasi merupakan hal yang esensi dalam program PKH. Verifikasi komitmenKeluarga Penerima Manfaat (KPM) merupakan kegiatan untuk mengecek kepatuhan KPM PKH terdaftar, hadir danmemperoleh/mengikuti layanan pada fasilitas kesehatan, fasilitas pendidikan, fasilitas kesejahteraan sosial yang tersedia.

Setiap bulan KPM PKH harus mengikuti serangkaian kegiatan yangtelah 
ditetapkan dalam mekanisme pelaksanaan $\mathrm{PKH}$. Serangkaian kegiatan itu tertuang dalam kewajiban KPM PKH dengan berdasar kepada komponen yang ada.

1) Komponen Kesehatan

a) Ibuhamil/ nifas, meliputi: (1) Pemeriksaan kehamilan sebanyak 4 kali dalam $3 x$ trimester; (2) Melahirkan oleh tenaga kesehatan;

Pemeriksaan kesehatan 2 kali sebelum bayi usia 1 bulan.

b) Bayi, meliputi: (1) Usia 0-11 bulan: Imunisasi lengkap; (2) Usia 6-11 bulan: Mendapat suplemen vitamin $A$.

c) Anak Usia Dini, meliputi: (1) Usia 1-5 tahun: Imunisasi tambahandan pemeriksaan berat badan minimal 2 kali dalam setahun; (2) Usia 5-6 tahun: Pemeriksaan berat badan minimal 2 kali dalam setahun dan mendapatkan Vitamin A sebanyak 2 kali dalam setahun; (3) Usia 6-7 tahun: Timbang badan difasilitas kesehatan minimal 2 kali dalam setahun.

2) Komponen Pendidikan

Kehadiran minimal $85 \%$ dalam 1 bulan bagi anak KPM yang bersekolah di SD,SMP,SLTA.

3) Komponen Kesejahteraan Sosial Lansia dan DisabilitasBerat wajib melakukan pemeriksaan kesehatan minimal satu tahun sekali dan mengikuti kegiatan pelayanan kesejahteraan sosial (day caredan home care).

4) $\mathrm{KPM} \mathrm{PKH}$ wajib menghadiri Pertemuan Kelompok atau Pertemuan Peningkatan Kemampuan Keluarga (P2K2).

Komitmen KPM terhadap layanan pendidikan, kesehatan, kesejahteraan sosial dan kehadiran dalam pertemuan kelompok secara rutin menjadisalahsatu komitmenyangharusdipenuhioleh setiap KPM. Seperti yang disampaikan Bapak Jasman,Koordinator PKH Kota Pekanbaru:

"Kegiatan verifikasi merupakan bagian dari tugas rutin setiap SDM PKH. Verifikasi memastikan setiap peserta PKH memenuhi setiap kewajiban yang melekat pada setiap komponen yang meraka dapat. Jika

Volume 4, Nomor 1, Pebruari 2020 kewajiban ini tidak dilaksanakan maka akan berpengaruh ke bantuan program yang ditangguhkan sampai kepada dikeluarkannya KPM dari peserta PKH." (wawancara, 20 Desember 2019)

Hasil verifikasi senjutnya di laporkan ke dalam E-PKH, dimana setiap pendamping memiliki username dan password. Disinilah yang selalu menjadi persoalan bagi pendamping, karena pada setiap penginputan hasil verifikasi selalu terkendala jaringan. Terkadang tidak jarang pendamping harus menginap di kantor. Keterangan ini di sampaikan Bapak Adi,Pendamping PKH Kec. Tampan:

"Setiap kali penginputan data di $E$ PKH kami sealalu mendapati jaringan yang lemot, terkadang kami harus menginap dikantor dan menunggu tengah malam hingga subuh untuk mendapatkan jaringan yang baik." (wawancara, 31 Desember 2019)

Hal senada juga disampaikan Bapak Yusuf,Pendamping PKH Kec. Tenayan Raya, beliau mengatakan:

"Ini sesuatu yang sulit bagi kami, jika kami tidak melakukan verifikasi komitmen, sementara KPM melakukan kewajibannya maka sistem akan menganggap KPM tersebut tidak komit dan berujung pada penangguhan bantuan. Sementara beberapa dari kami ada yang memiliki dampingan lebih dari 250 KPM."(wawancara, 9 Desember 2019)

Pelaksanaan $\mathrm{PKH}$ berikutnya adalah pemutahiran data KPM. Pemutahiran data dilakukan setiap ada perubahan sebagian atau seluruh data anggota KPM. Pemutahiran data mencakup hal-hal seperti: (1) Perubahan alamat tempat tinggal; (2) Kelahiran anggota keluarga; (3) Kematian anggota keluarga; (4) Masuknya anak-anak baruke sekolah; (5) Ibu hamil dan (6) Perbaikan dokumen-dokumen (menikah, cerai, meninggal, pindah tempat tinggal, dll).

\section{Transformasi Kepesertaan}

Transformasi kepesertaan $\mathrm{PKH}$ merupakan proses pengakhiran sebagai Keluarga Penerima Manfaat (KPM) PKH yang dilihat dari hasil evaluasi status kepesertaan dan sosial ekonominya. KPM $\mathrm{PKH}$. KPM dengan status ekonomi miskin dan masih memiliki komponen kepesertaan masih akan mendapatkan bantuan. Hal ini 
disampaikan Bapak Dirjen Limjamsos ketika berkunjung ke Pekanbaru, berdasarkan hasil wawancara peneliti dengan Bapak Firman selaku APD Pekanbaru:

"KPM PKH yang kondisi ekonominya masih kurang mampu tetap akan kita lanjutkan bantuannya, tentu dengan catatan KPM tersebut masih memiliki komponen." (wawancara, 15 Desember 2019)

KPM PKH yang memiliki status ekonomi lebih baik atau tidak memiliki komponen kepesertaan lagi meraka akan di graduasi. Graduasi terdiri atas graduasi hasil pemutakhiran sosial ekonomi dan graduasi mandiri.BeberapaKPMPKH yang berinisiatif untuk keluar dari kepersertaan $\mathrm{PKH}$ karena kesadaran sendiri dan menganggap masih banyak keluarga lain yang lebih pantas menerima bantuan, Bagi mereka dinamakan graduasi mandiri.

Hasil wawancara dengan ibu Rahma yang bertugas di kecamatan Marpoyan Damai mengatakan:

"Selama tahun 2019 di dampingan saya ada sekitar 35 KPM yang mundur dari kepesertaan PKH (graduasi mandiri). Walau demikian mereka tetap ingin hadir di pertemuan $\mathrm{PKH}$ karena menganggap banyak informasi dan ilmu yang mereka peroleh dari pertemuan peningkatan kemampuan keluarga (P2K2)."'(wawancara, 24 Desember 2019)

Diharapkan kedepan lebih banyak lagi KPM yang mampu maupun yang graduasi mandiri untuk keluar dari kepesertaan sehingga hal ini dapat berimbas terhadap penurunan angka kemiskinan dikota Pekanbaru.

\section{Kesimpulan}

Implementasi Program Keluarga Harapan (PKH) di Kota Pekanbaru sudah berjalan sesuai dengan Pedoman PKH Tahun 2019. Hal ini ditunjukan dengan:

1. KPM PKH Kota Pekanbaru sudah tepat sasaran sebagaimana ditujukan untuk keluarga miskin. Hal ini dapat terwujud karena kinerja dan peran fasilitator/pendamping yang baik.

2. Dalam pertemuan kelompok KPM PKH tidak haya hadir sebagai pemenuhan kewajiban namun juga karena adanyakesadaranmanfaat pendidikan dankesehatan bagi anakdalamkeluarga PesertaPKH.

3. Program Keluarga Harapan sangat berperan dalam mengurangi kemiskinan, hal ini ditunjukan dengan meningkatnya jumlah KPM yang Graduasi Mandiri atau keluar dari kepesertaan karena sudah mampu secara ekonomi.

\section{Saran}

Adapun saran peneliti dalam meningkatkan pelaksanaan PKH di Kota Pekanbaru adalah sebagai berikut:

1. Dalam proses pemuktahiran data E$\mathrm{PKH}$ sistem sering lemot yang disebabkan pemutakhiran data dilakukan pendamping seluruh Indonesia, sebaiknya kedepan pendamping tidak menunda-nunda penginputan data verifikasi komitmen peserta $\mathrm{PKH}$. Selain itu perlu dibuat penjadwalan entri data/verifikasi komitmen untuk masing-masing daerah.

2. Pengambilan data KPM yang digunakan adalah dari BasisDataTerpadu(BDT)hasilPendataa nProgram Perlindungan Sosial(PPLS) tahun2015, data tersebut tidak realtime sehingga dikhawtirkan belum tepat sasaran, sebaiknya penentuan KPM di update minimal 1-2 tahun sekali berdasarkan data dari tingkat bawah, seperti RT/RW, Kelurahan dan Kecamatan.

3. Dalam mencapai tujuan PKH di bidang pendidikan dan kesehatan, meningkatkan status pendidikan anak usia sekolah, mengurangi tingkat pekerja anak, anak jalanan, putus sekolah, dan menjaga kesehatan janin ibu dan kesehatan balita, diperlukan kerja keras pendamping PKH di Kota Pekanbaru. Perlu dilakukan sosialisasi, motivasi, dan pengetahuan serta informasi tanpa bosan akan pentingnya pendidikan dan kesehatan, sehingga kesadaran dan perubahan perilakudari peserta/penerima $\mathrm{PKH}$ terbangun. 


\section{DAFTAR PUSTAKA}

Chambers, Robert.(1987). Rural Development-Putting the Last First. New York: Longman Scientific and Technical.

Edi Suharto, Membangun Masyarakat Memberdayakan Rakyat: Kajian Strategis Pembangunan Kesejahteraan Sosial dan Pekerjaan Sosial, Bandung: Refika Aditama,2017,63-64.

Irmayani dan Togiaratua Nainggolan. 2015. Coping Behaviour of Program Keluarga Harapan (PKH) Recipients Approaching The Exit Programln North Jakarta.

Kementrian Sosial. 2016. Pedoman Umum Pelaksanaan PKH tahun 2016.Jakarta

Kementrian Sosial RI.2019.Pedoman pelaksana PKH 2019. Jakarta:Tim Penyusun Pedoman Umum PKH Lintas Kementerian danLembaga.

Konig, S.1995

Thecostofmal nutrition.Techinal Support Group F.Hoffman - LaRoche Ltd. 4/0895 (2nd ed). No. 50623. Switzerland.

Moleong, L.J.(2016). Metodologi Penelitian Kualitatif Edisi Revisi. Bandung:PT.Remaja Rosda Karya.

Neuman, W. Lawrence. (2006). Social Research Method: Qualitative and Quantitative Approaches. $6^{\text {Th }}$ Edition. USA: Pearson Education, Inc.

Permensos Nomor 146 tahun 2013

Republik Indonesia.(2018).Permensos Nomor 1 Tahun 2018 tentang Pelaksanaan Program Keluarga Harapan. Jakarta: Kementerian Sosial.

Republik Indonesia. (2017). Peraturan Presiden No.63 Tahun 2017 tentang Penyaluran Bantuan Sosial Non Tunai. Jakarta: Kementerian Sosial.
Sagala, S., Yamin, D, Pratama, A., Rianawati, E. Adaptive Social Protection, Disaster Risk Reduction and Sustainable Community Resilience: Evidence from RuralAreas in Indonesia. EditedBookBy Drolet,J.to be publishedin2016 byFrancis \&Taylor.

Salim, Agus. (2006).Teori dan Paradigma Penelitian Sosial:Buku Sumber Untuk Penelitian Kualitatif. Yogyakarta:Tiara Wacana.

Sen, A. (2001). Developmentas Freedom. Oxford: Oxford University Press.

Stampini, M.and Tornarolli,L.(2012).“The Growth of Conditional Cash Transfersin Latin America and the Caribbean: Did They Go Too Far?" IDB Policy Briefn.185.Washington D.C., USA: Inter-American Development Bank.

Sugiono. (2007). Metode Penelitian Kuantitatif Kualitatif Dan $R$ \&D. Bandung: Penerbit Alfabeta.

Tangkilisan, Hessel Nogi. (2003). Implementasi Kebijakan Publik. Jakarta: Lukman

Tuwu, Darmin. (2018). The Challenges ofMadani (Civilized) Brotherhood Program on Overcoming Poverty in The City of Kendari. IOP Conference Series: Earth and EnvironmentalScience. IOP

UUD 1945 Publishing.

World Bank. (2009). Conditional Cash Transfers Reducing Present And Future Poverty. WashingtonDC. 